\title{
Tradición oral ḥassāní: el léxico nómada de las adivinanzas
}

\author{
Ḥassāní oral tradition: the nomadic lexicon of the riddles
}

\author{
Ahmed Salem Ould MOHAMED BABA \\ Universidad Complutense de Madrid \\ aouldmoh@ucm.es
}

Recibido: 31 de enero de 2015

Aceptado: 28 de abril de 2015

\section{RESUMEN}

Este artículo contiene el léxico nómada de las adivinanzas ḥassāníes las cuales forman parte de la tradición oral ḥassāní.

Palabras clave: Dialectología árabe, Léxico ḥassāní, Tradición oral ḥassāní.

\begin{abstract}
This article contains the nomadic lexicon of the Ḥassāní riddles which are part of Ḥassāní oral tradition.

Keywords: Arabic dialectology, Ḥassāní lexicon, Ḥassāní oral tradition.
\end{abstract}

SUMARIO: 1. Introducción, 2. Adivinanzas, 3. Breve comentario sobre el léxico de este corpus de adivinanzas. 


\section{INTRODUCCIÓN}

La tradición oral está formada por todas las manifestaciones orales de un pueblo determinado: canciones, coplas, nanas, poesía popular, cuentos, acertijos, adivinanzas, etc.

Los beduinos hassāníes conservan en su memoria colectiva gran parte de esta tradición oral.

En este artículo, se presenta una colección de adivinanzas relacionadas con el mundo beduino, recogidas entre los nómadas hassāníes de la Wilāya de Trārza (suroeste de Mauritania). Se trata de fórmulas que los niños memorizan a modo de juego mediante el cual aprenden parte de su lengua contribuyendo así a la conservación de un patrimonio cultural ancestral.

En el caso que nos interesa aquí, sabemos que estas adivinanzas son relativamente antiguas porque aluden a objetos y hechos hoy casi inexistentes, debido, entre otras razones, al proceso rápido de sedentarización a la que se ha sometido la sociedad biợāni $\bar{l}^{1}$ desde hace varias décadas. Este tipo de expresiones fijas, que recibe en el dialecto hassāniyyä el nombre de thăaži ${ }^{2}$ (singular: thăažiyyä), era muy frecuente entre los beduinos que, cuando las circunstancias lo permitían, solían organizar veladas en las que un grupo de niños y jóvenes escuchaban con atención a un adulto que les preguntaba las adivinanzas a las que debían contestar individualmente.

A la expresión castellana "adivina adivinanza...", le corresponde en ḥassāniyya: “hāăäyt-ak mā žäyt-ak...”.

La mayoría de las adivinanzas tiene su propia rima para facilitar su memorización. Algunas de estas adivinanzas utilizan la onomatopeya para conseguir la rima y la musicalidad, que tanto gusta a los niños y les ayuda a recordarlas. En cuanto a su léxico, se hace referencia esencialmente a la vida cotidiana de los beduinos.

\section{ADIVINANZAS}

Hemos empleado en algunas adivinanzas la fórmula que se usa ante toda adivinanza (hāazäy-tak $m \bar{a} \check{z} a ̈ y t-a k \ldots$..), dejando las demás adivinanzas sin ella para ahorrar espacio. Las soluciones de las adivinanzas aparecen entre corchetes y, en el texto traducido, van precedidas de la letra S. (=solución).

1. hāaž̈äy-tak mā žäyt-ak: žäml-i l-ahmar bu-gäyd mgașșar xbaț̣u b-əssonbal žāni yonbəl xbattu b-al- 'anbar žāni yäb ar xbatțu b-āskūt ${ }^{4}$ gäyyäl biyyä Mäkkätä w-Afțūt ${ }^{5}=[$ [ət-tวxmām $]$

${ }^{1}$ El adjetivo biợn̄̄ se emplea para referirse a la población mauritana de origen árabe para distinguirla del resto de la población de origen africano. Se aplica asimismo genéricamente a todos los hablantes del hassāniyya, con independencia del país donde vivan.

${ }^{2}$ En árabe clásico se emplean los términos 'uhžiyya y luğz, aunque este último término se emplea más para referirse al enigma.

${ }^{3}$ Lit.: "Te hago una adivinanza y no voy a ti”. Compárese con la expresión clásica hužayyāka mā/fí ...

${ }^{4}$ Es una cuerda hecha con tiras de la corteza de algunos árboles. 
"Mi camello rojo, el de la traba corta, le di un golpe con un jacinto vino a mi cavando, le di un golpe con ámbar vino a mi defecando, le di con una cuerda me llevó en un día a la Meca y Āfțūț". S. [El pensamiento].

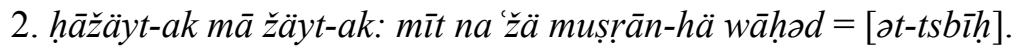

"Cien ovejas que tienen un solo intestino". S. [El rosario ${ }^{6}$.

3. xaḍ̛a w-mnäyylä w-tợall mgäyylä = [al-hadžä] .

"Verde y añil y pasa el día sesteando". S. [La sandía].

4. hâažäyt-ak mā žäyt-ak: Vātmä Mint al-'Abbās stäbba'-hä miyyä w-mitäyn raggāṣ $=[$ [ən-nžūm w-ol-qamar $]$.

"Vaṭmä Mint əl- 'Abbās la siguen cientos y cientos ${ }^{7}$ de bailarines". S. [Las estrellas y la luna].

5. hāǎääy-tak mā žäyt-ak: țbäl mlān mn-iyurš̌̌š kbar-hä 'slkä wahdä = [ən$n z ̌ u ̄ m ~ w$-al-qamar].

"Un harnero lleno de trozos de goma arábiga, la más grande es una 'alkä 8". S. [La luna y las estrellas].

6. hāăäy-tak mā žäyt-ak: 'lāš žäyta-k= [əl-kar'ayn]

"Adivina adivinanza, ¿Sobre qué vine a ti?" S. [Los pies].

7. mīt kwäyriyy $\ddot{a}^{9}$ taht sdäyriyyä $/^{10}=[$ əən-nmal $]$.

"Cien negritas debajo de un arbolillo". S. [Las hormigas].

8. hāãžäyt-ak mā žäytak: twīl b-lā ọall = [la-mrīrä] .

"Largo mas no tiene sombra". S. [El camino].

9. iṛā $i$ vì-k mā igadd $i \check{z} \bar{l}-k=[l-\bar{u} t \partial d]$.

"Te ve mas no puede ir hacia ti".S. [La estaca].

10. yä 'rặ l-ət-təh̆lāb w-lā iợūg-u = [l-ə 'mūd al-gaddāmi" $]$.

"Llega el primero al ordeño mas no lo cata". S. [El palo situado en la entrada de la jaima].

\footnotetext{
${ }^{5}$ V. Revue Mauritanienne de Géographie, no 1, año 1992, pág. 54, "región costera de Mauritania".

${ }^{6} \mathrm{El}$ rosario musulmán tiene cien cuentas.

${ }^{7}$ Lit.: "Cien y doscientos".

${ }^{8}$ Se refiere a una pieza entera de goma arábiga; si aparece en trozos, debido a la facilidad de romperse cuando está seca, se denomina /ivuršāšs/.

${ }^{9}$ kwäyriyyä es el diminutivo de käwriyyä "negra africana".

${ }^{10}$ sdäyriyyä es el diminutivo de șadṛāyä "árbol".

${ }^{11}$ La jaima está sostenida por una serie de maderos colocados en distintos puntos de la misma; la entrada está sujeta por un madero largo al que se refiere aquí la adivinanza.
} 
11. šwēbbtäyn yäxəngu bü-hum $=\left[\right.$ rr-rkāyaz w-əl-hummāar $\left.{ }^{12}\right]$

"Dos jovencitas que estrangulan a su padre". S. [los rkāyəz $z^{13}$ y al-hummāa $\left.r^{14}\right]$.

12. gädḩat yatța mā tankvä w-lā tugiatța = [al-hâasi $]$

"Una pequeña gädh $a^{15}$ que no se vuelca ni se tapa". S. [El pozo].

13. šað̛yat krātạta māšyä tatwātta = [la-grāàd].

"Un trozo de gratén que va andando". S. [Una garrapata ${ }^{16}$.

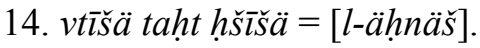

"Un poco de leche cuajada ${ }^{17}$ debajo de una mata de hierbas secas". S. [La serpiente].

15. nāgt-i nāgat al-Bū liyyä tarvad miyyä 'lä miyyä w-tgūl häḅb räyyāḥ mäggäl mā 'liyyä $=$ [/ət-trāāb/].

"Mi camella es camella de Bū liyyä'18, lleva cien(tos) y cien(tos) y dice ¡Aúpa! ¿Qué poco llevo? S. [La tierra].

16. šrä bägra māši yägra $=[\partial s-s a ̈ y l]$.

"Se compró una vaca para ir a estudiar". S. [El torrente].

17. hawliyyä mnäyn nälabsu yəždād w-mnäyn nävasxu yadras = [lə-mrīrä]. "Mi turbante, si me lo pongo, se vuelve nuevo y si me lo quito se vuelve viejo". S. [El camino].

18. muhr äzrrag yətragrag yəngaḅ əš-šäwk w-ixalli arr-ṛagg = [əl-mungās̄ $]$.

"Un ciervo moteado se estira, come las espinas y deja las hierbas de la llanura". S. [El mungā̄s $\check{s}^{19}$, o pinzas para sacar las espinas].

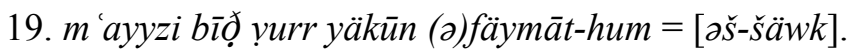

"Mis cabras son enteramente blancas excepto sus morros". S. [Las espinas ${ }^{20}$.

\footnotetext{
${ }^{12}$ al-hump̣ār; esta pieza de forma curva se adapta a la jaima y tiene dos agujeros donde se colocan los $r k \bar{a} y \partial z$, o pilares.

${ }^{13}$ Se trata de los dos pilares centrales que sostienen la jaima y que van unidos mediante una pieza hecha de madera, llamada al-hummmār (v. n. anterior)

${ }^{14} \mathrm{~V}$. nota anterior.

${ }^{15}$ Es un cuenco hecho de madera y usado, entre otras cosas, para servir la leche.

${ }^{16}$ Concretamente la especie más pequeña de garrapatas, de color negro.

${ }^{17} \mathrm{El}$ parecido entre la serpiente y la leche cuajada se establece porque la leche cuajada se cuartea y deja entreverse una forma que se parece al dibujo que tiene la piel de la serpiente.

${ }^{18}$ Nombre propio.

${ }^{19}$ Es una especie de pinza usada por los nómadas para sacar las espinas que se les clavan en el cuerpo; se abre en forma de cruz, usándose la parte puntiaguda para abrir la piel y la parte en forma de pinza, para sacar la espina.

${ }^{20}$ Se trata de las espinas del acaciar que son de color blanco salvo su punta que suele ser de color marrón.
} 
20. thäg mn-ad-dgìg ibadd 'lä vrìg = [al-qamar].

"Un harnero lleno de harina que basta para un campamento". S. [La luna].

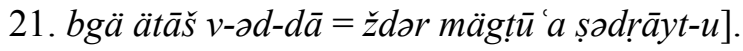

"Se quedó como un bastón en el lugar donde moraba el campamento". S [Un tronco cuyo árbol ha sido cortado].

22. țwìl mā yägla' 'alkä = [ər-ř̌ä $]$.

"[Palo] largo ${ }^{21}$ mas no sirve para recoger la goma arábiga". S. [La cuerda del pozo].

23. ärba 'äxūt v-darbālä $=[b z \bar{a} z \bar{l} l$ an-nāgä $]$.

"Cuatro hermanos en un harapo". S. [Las cuatro ubres de la camella].

24. žämli l-așvar bu-gäyd mgașsar rașșaf la-bhar w-dägdäg la-kșar $=[\partial r-$ rīh ol-hamra].

"Mi camello de color amarillo22, el de la traba corta, saltó por encima del mar y destruyó la aldea". S. [La tempestad de arena].

25. ärba' mtāạrəg v-wād ġārəg = [bzāzīl əl-bägra ].

"Cuatro balas en un valle profundo". S. [Las ubres de la vaca].

26. ždäyy argat māši yașaggat $=[$ tälmīdi al-xatmä $]$.

"Un cabrito moteado que va mendigando". S. [Un alumno que ha finalizado un rub 'del Corán ${ }^{23}$.

27. rāh al-bāroh șbah sārah = [al-gādūm].

"Vino anoche, y hoy va a pastorear". S. [El hacha].

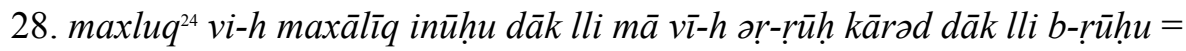
[ar-rbag].

"Una criatura contiene criaturas que se están quejando, la que no está viva sujeta a las que están vivas". R. [El $r b a g^{25}$ ].

\footnotetext{
${ }^{21}$ Para recoger la goma arábiga de las ramas altas del gomero, se emplean unos palos largos que llevan en la punta una pieza metálica afilada (llamada waxð̣a) que arranca la resina de las ramas para que sea recogida del suelo.

${ }^{22} \mathrm{El}$ color amarillo hace referencia a la arena que arrastra la tormenta.

${ }^{23}$ Los alumnos de las escuelas coránicas tienen por costumbre, cuando memorizan una cuarta parte del Corán, el llevar un läwh (tabla para aprender el Corán) con un dibujo coloreado llamado xatmä para solicitar una ayuda para su escuela y sus compañeros. Las personas que les ofrecen la ayuda pueden pedirles que reciten alguna azora para comprobar que han memorizado efectivamente el texto coránico. Algunas veces les preguntan una zärgä, o acertijo.

${ }^{24} \operatorname{maxl} \bar{u} q$ significa "criatura" y se usa eufemísticamente para "serpiente", en este último sentido está utilizada aquí, por el parecido entre la largura de la serpiente y la del rbəg, (v. infra).

${ }^{25} \mathrm{rbag}$ es un conjunto de sogas fijadas separadamente a una cuerda tendida entre dos estacas. Cada soga sirve para sujetar un cabrito o un corderito.
} 
29. yäḥläb ət-tahlāa b w-la iợūg-u= [äzäzzāy $]$.

"Ayuda ordeñar pero no prueba la leche". S. [El äzäzzāay $y^{26}$.

30. ždäyyti ždäyyat damyān mäksūṛa man läwwrra w-man al-gaddām rāakabhä buž r $r \bar{a} n$ w-igūd-hä Ahmäd 'Udān= [ad-dənyä] .

"Mi cabrita es una cervatilla cuyas patas traseras están rotas igual que las delanteras, va montado en ella un escarabajo y lleva su rienda una mantis religiosa". S. [La vida].

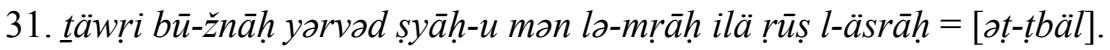
"Mi toro que tiene la pata delantera blanca va mugiendo desde el aprisco hasta los pastizales". S. [El atabal].

32. muxālaf muwālaf mațrūh bäyn lo-xwālaf $=[$ la-xțêr $]$.

"Desordenado, ordenado, dejado entre los $x w a \bar{l} l \partial \mathrm{f}^{27}$. S. [El $x t \bar{e}^{28} \underline{r}^{28}$ palanquín].

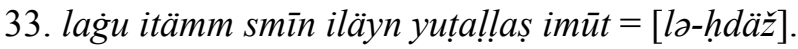

"Un rebaño de cabritos que, estando atados se mantienen gordos y, cuando se sueltan, mueren". S. [Las sandías].

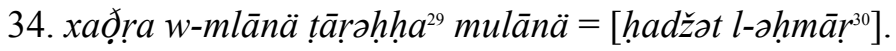

"Verde y llena allí la dejó Dios". S. [La sandía silvestre].

35. ibal xađ̛̣a kāmal-hä yäkūn žmāl-hä = [äbäylä] .

"Un rebaño de camellos todos de color oscuro, excepto los machos". S. [La äbäylä $\ddot{a}^{31}$.

36. ībl-i ìbal ngīrä mā täwkäl r rbì az-zīrä w-lā tašrab mä žhīrä = [la-mzūn]. "Mi rebaño de camellos está compuesto de camellos buenos, no comen las hierbas de las dunas ni beben agua de pozos". S. [Las nubes].

37. khäyl mlān mn-əs-swāl $f=$ [əl-' ‘kkä] .

"Un viejo que tiene muchas trenzas" S. [La ' $\left.\partial k k \ddot{a}^{32}\right]$.

\footnotetext{
${ }^{26}$ Cuerda que se usa para atar el ternero a la pata delantera de su madre mientras se ordeña a ésta. Según la creencia popular, la vaca produce más leche cuando está en contacto con su hijo.

${ }^{27}$ Los $x w \bar{a} l \partial f$, (plurar de $x \bar{a} l v \ddot{a}$ ), son cada uno de los vientos que sujetan la jaima.

${ }^{28} l a-x t e \bar{e}$, es un palanquín usado para transportar a las mujeres encima de los camellos, a parte de la comodidad que proporciona, protege de las ramas de los árboles y del sol.

${ }^{29} /$ țāṛhḥha/ (</țāṛ̂h / + /ha/).

${ }^{30}$ Es un tipo de sandía silvestre incomestible llamada popularmente "sandía del asno" por ser el único animal que la come. Su identificación botánica es Citrillus colocynthis y su nombre en árabe clásico es al-ḥanḍal.

${ }^{31}$ Es el nombre de una planta.

${ }^{32}$ Es un recipiente hecho con la piel de un cordero y que sirve para guardar ad-dhən "la manteca".
} 


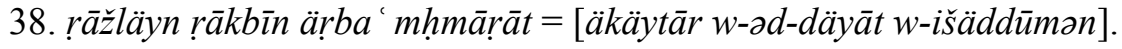

"Dos hombres van montados en cuatro burras". S. [/äkäytār ${ }^{33}$, ad-däyāt ${ }^{34}$, išäddūmən $\left.n^{35}\right]$.

39. twäys mbukər täwkäl aṣ-ṣakkar $=[\ddot{a} b \ddot{a} r r a \bar{a} d]$, "Una vaquita joven [que ha parido una vez] que come azúcar". S. [La tetera].

40. 'anz ävarțās täl 'ab b-lā ṛās = [ət-täwd].

"Una cabra sin cuernos juega sin cabeza". S. [täwd $\mathrm{d}^{36}=$ pelota].

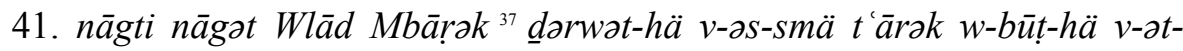
trāa b yäžhar la-mbār $ə k^{38}=[$ [az-z̧a yäygä] $]$.

"Mi camella es la camella de Wlād Mbāṛ̂k, su joroba está en el cielo peleando y su ombligo en la tierra cavando trincheras". S. [El vendaval].

42. därrrāa ti mnäyn nalbas-hä taždād w-mnäyn nävsaxxa ${ }^{39}$ tadras $=$ [əț-trīg $]$. "Mi därrạa ' $a^{40}$ si la llevo se vuelve nueva y si me la quito se vuelve vieja". S. [El camino].

43. 'anzi ḥamṛa tamši tärdaḥ w-tži tärdah nämlä mən-hä šakwä w-gdah = [əs-shāa $\bar{b}]$.

"Mi cabra roja se va a jugar y vuelve jugando; la ordeño y me llena una šakwä ${ }^{41}$ y una fuente". S. [La lluvia].

44. näyräb b-axṛāṣ-hä rāvdä as-smä 'lä rạṣs-hä = [əl-jaymä].

"Una liebre que lleva pendientes, sostiene el cielo sobre su cabeza". S. [La jaima].

45. /d̄āku wäyn-hu/= [lə-braga]. "Allí está ¿Dónde está?". S. [El relámpago].

${ }^{33}$ Mueble nómada confeccionado con una tela muy resistente a la que se le colocan dos palos, llamados išaddūmən, uno a cada lado a modo de camilla; la cual, se apoya sobre cuatro horquillas, llamadas $ə d$-däya $\bar{t}$, clavadas en el suelo. De este modo, se consigue proteger los enseres de carcomas y otros insectos.

${ }^{34} \mathrm{~V}$. nota anterior.

${ }^{35} \mathrm{~V}$. nota anterior.

${ }^{36}$ Una pelota hecha con piel de cabra y rellena de lana y telas. Se juega habitualmente con unos palos, parecidos a los utilizados para el golf, llamados gंawrāvä, (pl. ġawrävāt). El juego se organizaba por las tardes, entre dos equipos que pueden ser de dos campamentos distintos, no tiene guardameta y la portería suele ser dos árboles o dos palos clavados en el suelo. El equipo que consigue pasar la pelota entre los dos puntos gana el partido, pero el juego sigue hasta que todos los jugadores decidan poner fin al juego; suele ser al atardecer.

${ }^{37}$ Tribu que le correspondía históricamente la Imāra de la Wilāya de Bṛāknä (sur-este de Mauritania actual).

${ }^{38}$ Obsérvese la diferencia entre Mbāṛk (nombre propio) y mbārək, plural de mäbräk "trinchera"; ambas palabras constituyen un par mínimo para diferenciar los dos fonemas $/ \mathrm{r} / \mathrm{y} / \mathrm{r} /$.

${ }^{39}$ Obsérvese la asimilación: /nävsaxxa/ < (/nävsax/ + /hä/).

${ }^{40}$ Se trata de la túnica típica que llevan los hombres biợan, o hassāníes, con independencia del país donde vivan (Mauritania, Sáhara, Malí, Senegal, etc.).

${ }^{41}$ Especie de odre hecho con la piel de un cabrito y que se usa para guardar la leche. 


\section{BREVE COMENTARIO SOBRE EL LÉXICO DE ESTE CORPUS DE ADIVINANZAS}

Desde el punto de vista del léxico, se observa que, como es lógico en un texto beduino:

- La presencia de un vocabulario casi especializado en la vida nómada, v.gr., ütəd "estaca"; rkāyəz "pilares de la jaima"; vrīg "campamento"; vtǐšä "leche cuajada"; nāgä "camella"; bägra "vaca"; muhr "ciervo"; gäyd "traba de camello"; šawkä "espina"; tbäg "harnero"; ždäyy "cabrito"; täwr "toro"; ibal "camellos"; twäys "vaquita"; žmäl "camello"; žhīrä "pozo"; yähläb "ordeña"; al-xaymä "la jaima"; ar-rhīl "el desplazamiento del campamento"; sārəh "que pastorea", hmmārāt "asnas"; 'anz "cabra"; näyräb "liebre", etc.

- Hay algunas voces bereberes, /äzäzzāy/ "cuerda utilizada para atar el ternero a la pata delantera de su madre durante el ordeño". 